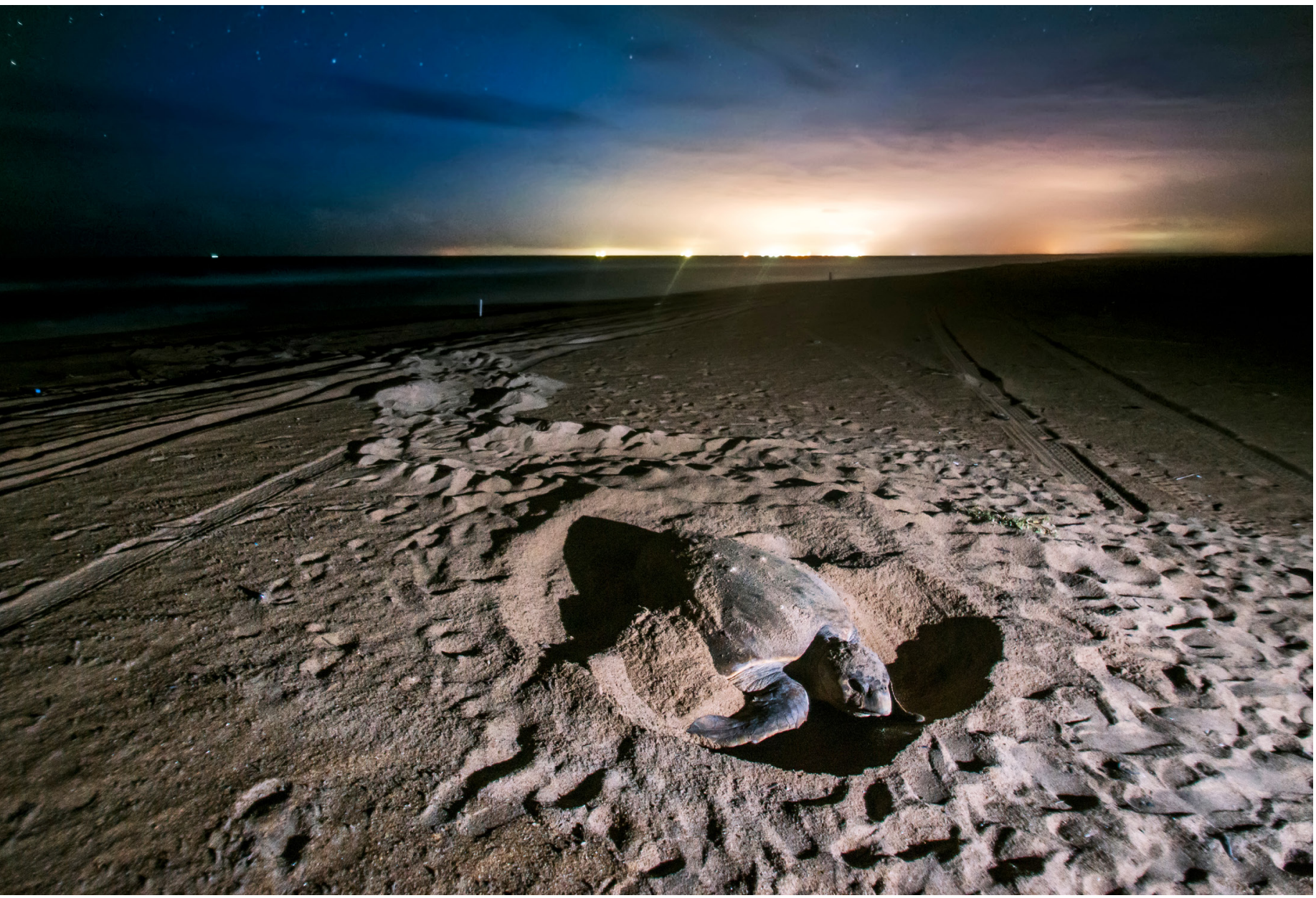




\section{Soluções Empreendedoras e Capacitação Profissional: Empreendendo o "Pensionato Da Sueli"}

Entrepreneurial solutions and professional training: undertaking with the "Sueli's Boardinghouse"

\section{Resumo}

Este artigo descreve as ações do projeto de extensão que trata da capacitação profissional de microempreendedores, cujo objetivo é desenvolver atividades empreendedoras, almejando auxiliar pequenos empreendimentos na gestão de seus negócios. As atividades foram desenvolvidas no Pensionato da Sueli, com o intuito de suprir as dificuldades encontradas na gestão financeira, na divulgação do empreendimento e, consequentemente, na escassez de clientes. Inicialmente foi realizada uma visita ao estabelecimento com todos os extensionistas para melhor conhecer o ambiente e as dificuldades existentes; posteriormente, realizou-se uma roda de conversa, utilizando a metodologia de Brainstorming, onde a equipe do projeto de extensão pôde fornecer ideias para a solução dos problemas encontrados. A principal sugestão foi priorizar o desenvolvimento da atividade de restaurante e marmitaria, para maximizar os lucros, gerando fluxo de recursos para cobrir as despesas da pensão. Com a seleção das ideias, foram realizadas capacitações sobre gestão financeira e estratégia de vendas com foco nas redes sociais, elaborando uma nova logomarca, cardápio para o restaurante e panfletos para divulgação do estabelecimento. Dessa forma, foi possível realizar a reestruturação do layout do pensionado, com a capacitação da proprietária para uma gestão financeira e profissional do estabelecimento, de acordo com as novas ações adotadas.

Palavras-chave: Empreendedorismo; Capacitações; Gestão Financeira; Pensionato.

Janaina Ferreira Marques de Melo* Vorster Queiroga Alves Geovani de Almeida Santos

Universidade Federal de Campina Grande (UFCG) E-mail: janainafmmelo@gmail.com* 


\section{Abstract}

This article describes the actions of the extension project that deals with the professional training of microentrepreneurs, whose objective is to develop entrepreneurial activities, aiming to assist small enterprises in the management of their businesses. The activities were developed at Pension Sueli, in order to overcome the difficulties encountered in financial management, in the dissemination of the enterprise and consequently in the shortage of clients. Initially, a visit to the establishment was carried out with all the extension agents in order to better know the environment and the difficulties. Later, a discussion was conducted using the Brainstorming methodology, where the extension project team was able to provide ideas to solve the problems encountered. The main suggestion was to prioritize the development of restaurant and catering, to maximize profits, generating a flow of resources to cover pension expenses. With the selection of ideas, training was provided on financial management and sales strategy focused on social networks, elaborating a new logo, menu for the restaurant and pamphlets to publicize the establishment. In this way, it was possible to carry out the restructuring of the layout of the pensionado, with the qualification of the owner for a financial and professional management of the establishment, according to the new actions adopted.

Keywords: Entrepreneurship; Training; Financial management; Pension. 


\section{INTRODUÇÃO}

O mercado de trabalho de microempreendedores individuais é um dos que mais crescem atualmente no Brasil e têm causado impactos significativos na economia. Isso se deve a inúmeros fatores que ocorrem na economia do país, afetando diretamente a vida das pessoas como, por exemplo, o alto índice de desempregados, que impulsiona as pessoas a buscarem novos meios de sobrevivência, quer sejam formais ou informais, sendo o microempreendedorismo uma das alternativas mais procuradas, principalmente pela facilidade de inserção no ramo e autonomia gerencial dos empreendedores.

É considerado microempreendedor individual a pessoa que abre um negócio por conta própria, tomando para si a responsabilidade empreendedora da empresa. Por isso, o empreendedorismo é considerado pelos especialistas como vital para o sucesso profissional, pois considera o desenvolvimento e aperfeiçoamento de atitudes importantes para a gestão de ações perante as incertezas do cenário atual.

Microempreendedor Individual (MEI) é a pessoa que trabalha por conta própria e que se legaliza como pequeno empresário. Para ser um microempreendedor individual, é necessário faturar no máximo até $R \$$ 60.000,00 por ano e não ter participação em outra empresa como sócio ou titular. Entre as vantagens oferecidas por essa lei está o registro no Cadastro Nacional de Pessoas Jurídicas (CNPJ), o que facilita a abertura de conta bancária, o pedido de empréstimos e a emissão de notas fiscais. Além disso, o MEl será enquadrado no Simples Nacional e ficará isento dos tributos federais (Imposto de Renda, PIS, COFINS, IPI e CSLL). Assim, pagará apenas o valor fixo mensal de $R \$ 47,85$ (comércio ou indústria), $R \$$ 51,85 (prestação de serviços) ou R\$ 52,85 (comércio e serviços), que será destinado à Previdência Social e ao ICMS ou ao ISS. Essas quantias serão atualizadas anualmente, de acordo com o salário mínimo. Com essas contribuições, o Microempreendedor Individual tem acesso a benefícios como auxílio maternidade, auxílio doença, aposentadoria, entre outros [1].

Ter uma atividade empreendedora é demonstrar algumas atitudes específicas que caracterizam o perfil do empreendedor e, logo, concebe-se que o portador do perfil empreendedor é aquela pessoa capaz de identificar oportunidades, que é visionária, vendo além do que a maioria das pessoas veem, que persegue firmemente seu propósito, contagiando as pessoas à sua volta com seus ideais e que está disposta a assumir riscos [2]. Ensinar a empreender é possível, mas o segredo de aprender a empreender depende exclusivamente do candidato a empreendedor.

O projeto de extensão Capacitação Profissional para Microempreendedores (CPMEI) está vinculado à Unidade Acadêmica de Ciências Contábeis do Centro de Ciências Sociais e Jurídicas da Universidade Federal de Campina Grande (UFCG), no Campus Sousa - PB, no qual alunos dos cursos de Ciências Contábeis e Administra- 
ção participam de atividades da extensão. O objetivo do projeto é a capacitação e orientação profissional de microempreendedores individuais no processo de gestão dos seus empreendimentos.

Neste aspecto, observa-se a relevância de incentivar projetos de extensão direcionados para os microempreendedores, pois a missão de uma universidade pública está alicerçada no tripé do desenvolvimento das atividades de Ensino, Pesquisa e Extensão, objetivando a formação profissional de excelência, na perspectiva de um desenvolvimento sustentável, de integração com a sociedade e do exercício da cidadania.

Deste modo, o intuito do projeto CPMEl é dar apoio e atuar nas áreas vinculadas ao empreendedorismo, podendo ser a porta de acesso a outros benefícios, como a melhoria da escolaridade e da qualificação profissional, o desenvolvimento sustentável, a integração com a sociedade e no exercício da cidadania, elevação da autoestima e reinserção social, sendo uma troca de saberes entre empreendedores e extensionistas, essencial para o crescimento pessoal e formação profissional de todos os envolvidos.

Para o desenvolvimento do empreendedorismo, a questão da administração financeira é fundamental. Em pesquisa realizada no município de Sousa-PB, foi possível observar que os empreendedores individuais admitem ter falhas na gestão financeira do negócio, e que a desestruturação do planejamento financeiro dos empreendedores é proveniente da falta de informação de como se trabalhar financeiramente de forma organizada, evidenciada pela falta de capacitação ou participação em cursos de aprimoramento [3].

Neste sentido, além do planejamento financeiro, é preciso analisar todo o planejamento estratégico. Este é um processo dinâmico, onde são definidos caminhos que a empresa deverá trilhar por meio de um comportamento proativo, levando em conta a análise do seu ambiente e em consonância com a sua razão de existir, a fim de construir o seu futuro desejado [4].

O planejamento em uma organização é um processo relevante que enfatiza a sobrevivência e deve ser considerado um motivo de preocupação para os empreendedores. Neste sentido, é necessário haver um trabalho de conscientização da importância do planejamento para as empresas em cursos de empreendedorismo nas universidades [5], em incubadoras ou em parceria com o SEBRAE, como uma forma de despertar o interesse dos empreendedores.

Planejar uma empresa também envolve ações de marketing, por parte do empreendedor, que não se restringem à publicidade e propaganda e são compostas por ações de comunicação, ambientação da loja, inovação, atendimento, preço, promoção, localização entre outras, ou seja, toda e qualquer forma que ajude ao empreendimento a atração da clientela e resulte em sucesso para o negócio [6].

Logo, é possível que pequenos empreendimentos possam se utilizar de inúmeros instrumentos de divulgação, gastando pouco e obtendo bons resultados [6]. Dessa forma, as ações de marketing para o empreendimento trabalhado no proje- 
to, buscavam entender o contexto e o ambiente para sugerir ações que buscassem atender sua real necessidade, dentro de suas condições orçamentárias. Nesse sentido, o marketing é uma das mais importantes ferramentas para o pequeno empreendimento.

Tratando-se da relevância dos projetos de extensão para a formação acadêmica, o Fórum de Pró-Reitores de Extensão das Instituições Públicas de Educação Superior Brasileira [7], reafirmou a relevância das quatro diretrizes preconizadas no Plano Nacional de Extensão Universitária de 1999: Interação Dialógica, Interdisciplinaridade e Interprofissionalidade, Indissociabilidade Ensino - Pesquisa - Extensão, Impacto na Formação do Estudante e Impacto na Transformação Social.

A Interação Dialógica preconiza a relação entre a Universidade e a sociedade por meio do diálogo e da troca de saberes, desassociando do padrão estabelecido pela separação de classes e academia, por meio da união com movimentos, setores e organizações sociais. É notória essa união nas ações realizadas na extensão, em especial, neste projeto, visto que as ações desenvolvidas em grupos diversos da sociedade fomentam esta troca de saberes.

Já a Interdisciplinaridade e Interprofissionalidade almejam a combinação de modelos, conceitos e metodologias de diversas disciplinas e áreas de conhecimento, no intuito de construir alianças intersetoriais, interorganizacionais e interprofissionais. Neste sentido, percebe-se neste breve relato das ações executadas neste projeto, a união de disciplinas que resultam de diversas áreas da Administração e Ciências Contábeis como Empreendedorismo, Gestão de Pessoas, Marketing, Administração Financeira, Custos, Gestão de Estoques, dentre outros. As metodologias utilizadas foram de acordo com o público atendido, contribuindo na construção dessas alianças.

No que tange à Indissociabilidade do Ensino, Pesquisa e Extensão, desta diretriz decorre a maior efetividade de ações extensionistas no processo de formação de pessoas (ensino) e de geração de conhecimento (pesquisa). Assim, percebe-se nas vigências anteriores deste projeto, esta formação de pessoas (alunos, professores e sociedade) que disseminaram e trocaram conhecimentos entre si, fomentando ainda mais o ensino "fora dos muros" da universidade. A geração de conhecimento fomentada na pesquisa, estudos de campo, e artigos científicos corroboram com esta diretriz.

A diretriz que trata do Impacto da Formação do Estudante aborda o contato direto com questões contemporâneas, enriquecendo a experiência discente com termos teóricos e metodológicos, além da reafirmação dos compromissos éticos e solidários da Universidade Pública Brasileira. A participação do discente nas ações de Extensão Universitária deve estar sustentada em iniciativas que viabilizem a flexibilização curricular e a integralização de créditos. Neste caso, ainda não há esta flexibilização no currículo da UFCG, contudo, o projeto corrobora com o impacto na formação estudantil por meio das atividades por ele promovidas.

Tratando-se da última diretriz, o Impacto na Transformação Social, estabelece a inter-relação da Universidade com os outros setores da sociedade, com vistas a 
uma atuação transformadora, voltada para os interesses e necessidades da maioria da população, e propiciadora do desenvolvimento social e regional e de aprimoramento das políticas públicas. As ações transformadoras estão de acordo com as necessidades específicas do público atendido neste projeto, como pode ser percebido em cada relatório final da extensão, o qual aponta a satisfação com as ações empreendedoras e a participação de todos os envolvidos.

O público-alvo do projeto são empreendedores individuais formais e informais, agricultores e associações em geral. Todas as atividades foram desenvolvidas com o objetivo de auxiliar os pequenos empreendimentos no gerenciamento eficiente de seus negócios. Os alunos extensionistas dos cursos de Administração e Ciências Contábeis têm, por meio do projeto, a oportunidade de conciliar a teoria estudada nas salas de aula com a prática, trazendo experiências e benefícios enriquecedores para todos os extensionistas.

Dentre as atividades extensionistas realizadas com o público assistido, destacou-se em 2016, o trabalho realizado com a empreendedora Ana Sueli Cardoso, proprietária do "Pensionato da Sueli", do qual este artigo traz informações detalhadas.

\section{METODOLOGIA}

Com relação à metodologia proposta, para a coleta e análise dos resultados, inicialmente foi realizada uma pesquisa exploratória, para o levantamento de informações sobre o público assistido com vistas ao planejamento das capacitações. Esta etapa constou de visitas técnicas para conhecer a realidade do empreendimento antes das capacitações.

O desenvolvimento do projeto envolveu treinamentos, cursos e consultoria, bem como acompanhamento. Os professores orientadores buscaram acompanhar e atender às necessidades dos colaboradores (parceiros) e dos assistidos para orientação dos discentes envolvidos na execução das atividades.

A análise foi realizada por meio de reuniões periódicas na UFCG (salas de aula do Campus Centro), sendo que para a coleta e análise de resultados deste projeto foram levados em consideração:

A. Pesquisa sobre as necessidades dos colaboradores e assistidos (pesquisa exploratória- visita técnica para levantamento de informações para fundamentar as capacitações).

B. Avaliação do bolsista e de extensionistas, coordenador e orientadores (por meio de reuniões nas dependências da UFCG), em que ocorreram avaliações acerca do andamento das atividades, planejamento e análise das capacitações já ministradas.

Essas ações foram realizadas por meio da observação, sem tabulação de dados própria, com discussões em grupo e reuniões. Com o desenvolvimento das ativi- 
dades do projeto e novas metas propostas e alcançadas, houve um aprimoramento da metodologia para se traçar propostas, estudos de mercado, novas capacitações e consultorias específicas. Com base nas visitas e nas observações e necessidades do público assistido definiram-se as principais necessidades e problemas, para que posteriormente fossem discutidas as possíveis soluções. Deste modo, o planejamento das ações da equipe foi realizado por meio de uma reunião após a visita, na UFCG, no intuito de discutir as primeiras impressões sobre a associação e sugestões para melhorias, usando a técnica de Brainstorming.

O Brainstorming é uma técnica de recolha de informação muito utilizada na investigação em Ciências Sociais e Humanas, com o objetivo de explorar novas ideias sobre um tema ou alternativas de solução para problemas das mais diversas naturezas, sejam em organizações, empresas, negócios, etc [8]. Esta técnica revela mais potencial na medida em que as interações no grupo fazem despolitizar mais ideias do que as obtidas individualmente.

No caso, aplicou-se a técnica da seguinte forma: toda equipe pôde fornecer uma "avalanche" de ideias para a solução do caso. Estas foram anotadas e, em seguida, discutidas, verificando a sua viabilidade e delegando funções aos membros da equipe, para realizar pesquisas de mercado e estudos mais profundos adaptados à realidade da associação.

Para o alcance da viabilidade dessas sugestões, foram aplicadas atividades de pesquisa, divididas pela equipe para estudos de mercado e elaboração de Planos de Marketing e Planejamento Financeiros específicos para cada comunidade no intuito de solucionar os problemas e apresentar propostas.

\section{RESULTADOS}

No mês de maio de 2016, realizou-se a primeira reunião interna entre professores e extensionistas do projeto CPMEI 2016. Nessa reunião, foi ouvida a empreendedora Ana Sueli Cardoso, proprietária do "Pensionato da Sueli", que fica localizado no centro da cidade de Sousa-PB, ao lado da "Igreja Bom Jesus". Sueli está em meio a dificuldades financeiras ocasionadas pela pouca quantidade de clientes hospedados em sua pensão. Ela fornece três refeições, além de prestar serviço de lavagem de roupa e hospedagem 24 horas por dia. O tempo que cada hóspede ficaria no pensionato seria combinado com Sueli, e esse era um dos problemas enfrentados pela mesma, pois, segundo ela, os hóspedes querem ficar cada vez menos tempo, sem falar que os poucos que estão hospedados muitas vezes não respeitam as regras do pensionato, querendo chegar muito tarde, ingerir bebidas alcoólicas dentro do estabelecimento, dentre outros problemas.

Cada um dos extensionistas tiveram a oportunidade de compartilhar da experiência relatada por Sueli e de expressar opiniões e comentários. Após conversa com Sueli, foi acordada uma visita ao seu empreendimento ainda no mês de maio, o que assim ocorreu (Foto 1) a fim de se conhecer melhor as acomodações e realizarmos a entrevista para tratar dos seguintes assuntos: conhecer os serviços prestados, 
analisar os custos dos serviços prestados e de que forma é estabelecido o preço de venda e margem de lucro dos serviços, logística, perfil empreendedor, entre outros assuntos.

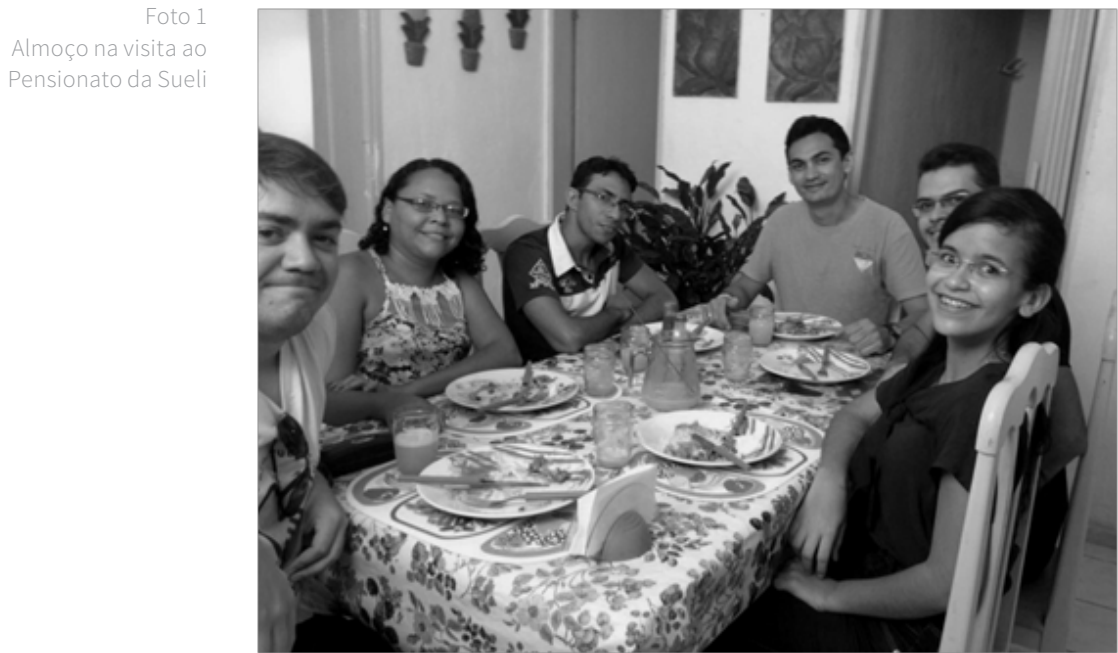

Durante a visita, Sueli relatou que possui altos custos para manter o funcionamento do seu pensionato, com um aluguel de $\mathrm{R} \$ 1.000,00$ (um mil reais) por mês, gastos com alimentação (onde segundo a mesma, compra uma grande quantidade de alimentos para não correr o risco de faltar comida para os clientes) e produtos de limpeza para manter sempre o pensionato limpo e organizado, sem falar que ela também lava as roupas dos hóspedes. Tendo em vista todos esses custos, Sueli informou que o preço cobrado, pela hospedagem em seu pensionato, custa a partir de $\mathrm{R} \$ 700,00$ (setecentos reais) mensais, preço consideravelmente baixo para tanto serviço prestado.

Uma ideia apresentada a Sueli foi a de investir mais no segmento de alimentação, passando a fornecer almoço dentro do pensionato e marmitas para consumo domiciliar. Dessa forma, o esforço dela seria reduzido pela metade (ou mais), e o lucro seria bem maior do que o apresentado com os serviços prestados, tendo em vista que ela poderia cobrar $\mathrm{R} \$ 10,00$ (dez reais) ou mais pelo almoço diário e os mesmos $\mathrm{R} \$ 700,00$ (setecentos reais) mensais para fornecer almoço diariamente com entrega a domicílio para os clientes, e não teria toda a preocupação de ficar 24 horas cuidando de hóspedes e sua alimentação, entre outras coisas.

De fato, ela já fornece para algumas pessoas o almoço e quando solicitado, café da manhã e jantar. Deste modo, Sueli aceitou a ideia, ficando bastante animada e pretende dar seguimento a este planejamento.

Outra situação apresentada, a carência de clientes, se deve ao fato de o pensionato da Sueli fazer parte de um mercado não muito procurado na cidade de Sousa/PB, onde as pessoas optam por morar em casas ou apartamentos. Outro agravante é o pouco investimento em divulgação. Suas instalações são ótimas e es- 
tão localizadas em um ponto privilegiado, no centro da cidade, próximo a bancos, supermercados, lojas, dentre outros. De acordo com o que foi relatado, o empreendimento não está tendo nenhum lucro, pois o preço cobrado de cada hóspede é consideravelmente baixo em relação aos gastos necessários para manter o funcionamento da pensão.

Durante a avaliação da situação, alguns pontos foram destacados para orientar as medidas que poderão ser posteriormente adotadas. São eles:

- Os Pontos fortes: a organização, limpeza do local, comida bastante saborosa, localização do pensionato, oferecimento de serviços de limpeza e lavagem de roupas dos inquilinos.

- Os pontos fracos: má gestão financeira, pois não se sabe quanto custa um pensionista por mês; a placa na fachada também deixa a desejar de maneira que se torna imperceptível para quem não conhece o pensionato ou a cidade.

Considerando as dificuldades relatadas e encontradas no Pensionato da Sueli, os extensionistas elaboraram algumas propostas para o empreendimento, as quais estão descritas a seguir:

- Divulgação nas rádios de Sousa (a UFCG tem dois programas na rádio educativa que poderia fazer a divulgação gratuitamente), na agenda online (baixo custo), rádio comunitária e carros de som;

- Buscar parcerias e ampliar a divulgação boca a boca;

- Oferta de planos (pacotes) variados referentes à pensão (diários, semanais ou até mensais);

- Divulgação por meio de panfletos (com ênfase nas faculdades particulares, UFCG, repartições públicas e estabelecimentos comerciais) em pontos estratégicos com grande circulação de pessoas. Fixação de cartazes em locais de circulação dos estudantes. Divulgação em redes sociais, mostrando os serviços oferecidos. Criação de página no Facebook.

- Criar um grupo de WhatsApp para seus clientes.

- Com o funcionamento de outras atividades, delimitar os horários para cada refeição dos pensionistas. Uma sugestão criativa de punição, para quem fizer a refeição fora do horário estabelecido, seria a lavagem de seu prato.

- Ampliação da placa na fachada da pensão.

- Oferecimento de refeições self service, marmitas e quentinhas para o público que não é pensionista.

- Oferta também de outro diferencial: refeições saudáveis como comida vegetariana, comida fitness, sucos naturais detox e fit ou para dieta, sem excluir a comida e o suco tradicional, com a ajuda de parceiros (profissionais 
da área da saúde e nutricionistas).

- Formalização do negócio como MEl, o que facilitaria a aquisição de um empréstimo para investir (a exemplo da Prefeitura Municipal de Sousa, onde é fornecido um empréstimo de R\$2.000,00 pelo programa "Fazer Negócio").

- Adquirir um balcão de self-service.

- Deste modo, precisa expandir seu negócio, mudando as características de seu empreendimento de pensionato para empresa de fornecimento de marmitas. Se possível, transformá-lo em um restaurante.

Com o levantamento das dificuldades e propostas para o empreendimento, verificou-se que o custo-benefício do pensionato possui poucas vantagens financeiras, diante do fato que ela trabalha 24 horas por dia e o preço cobrado é baixo por tanto serviço prestado, e se aumentar o preço será ainda mais difícil encontrar hóspedes. O fato é que, se cobrar mais barato vai ser muito serviço para pouco lucro. Como opção, abrindo um restaurante/marmitaria se trabalharia mais no turno da manhã e um pouco à tarde. No entanto, o preço cobrado precisa ser competitivo em relação aos concorrentes, tornando seu negócio mais lucrativo. Quem sabe, uma ideia seria aos poucos abrir mão do pensionato e focar em alimentação.

A partir da verificação de que o pensionado tinha pouca vantagem financeira, constatou-se que existia má gestão financeira, não sabendo sequer quanto custa cada pensionista por mês. Por isso, ficou programado ministrar a oficina "Fluxo de Caixa e Orçamento: Planejamento Financeiro". É certo que nenhum tipo de negócio consegue se manter com suas contas negativas, pois precisa obter lucro, ainda mais que ela se encontra atuando informalmente e sem nenhuma reserva para seu futuro (aposentadoria).

Após conhecer a realidade vivida pela empreendedora, foram propostas algumas melhorias pela equipe do projeto. A primeira foi a proposta de adesão ao segmento alimentício, com a abertura da marmitaria e ou restaurante da Sueli, com o objetivo de maximizar os lucros. Em seguida, destacou-se a necessidade de uma maior divulgação do negócio, a começar com divulgação gratuita nas rádios de Sousa (a UFCG tem dois programas na rádio educativa FM que poderia fazer a divulgação gratuitamente), assim como na agenda online (onde o custo seria baixíssimo) e em carros de som, e distribuição de panfletos (com ênfase maior na UFCG, em faculdades particulares, repartições públicas e estabelecimentos comerciais) e em locais com grande circulação de pessoas de outras cidades.

Outra orientação, como informado, foi a respeito da gestão de negócios, com a oferta de treinamento. A oficina "Gerenciamento das Finanças Pessoais e Empresariais" teve como conteúdo: "Introdução ao orçamento empresarial e pessoal"; "Conceitos e características das finanças pessoais"; "Taxas de empréstimos"; "Importância da administração financeira nos negócios"; "Prática de exercícios"; e "Dicas importantes sobre finanças". O objetivo desta oficina foi capacitar os extensionistas para que, posteriormente, possam ministrar palestras e oficinas sobre o mesmo 
tema, tanto para Sueli, como para outros empreendedores que estejam passando por situações financeiras semelhantes, de forma a se atingir o objetivo principal do projeto de capacitar empreendedores individuais, ou até mesmo outros empreendedores que trabalhem informalmente.

Após a oficina (Foto 2), decidiu-se pela formação de grupos entre os extensionistas, com o objetivo de dividir o planejamento e atividades que seriam realizadas a partir de então, de forma que todos pudessem participar de forma realmente efetiva na consultoria ao Pensionato da Sueli.

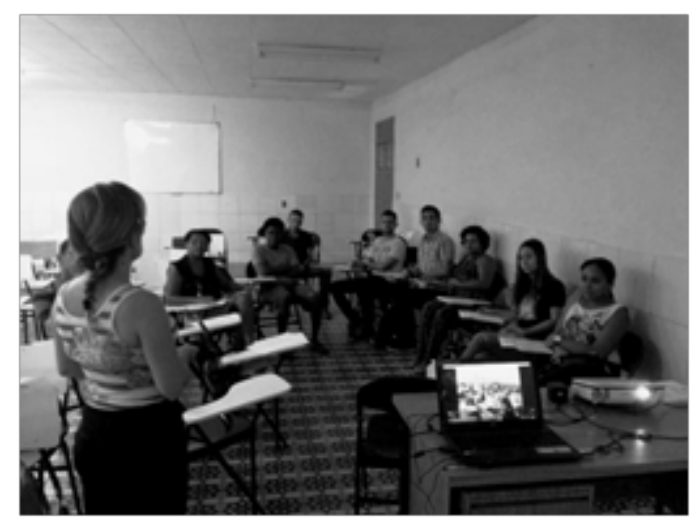

Na oportunidade, revelaram-se os pontos fracos e fortes, além de várias sugestões de melhoria, entre as quais, desenvolver nova atividade: restaurante e marmitaria. Foi realizada uma pesquisa de mercado para avaliar seus futuros concorrentes, análise de preços e custos para a inclusão da atividade, mudanças de lay out na sua casa, mudança de logomarca, nome e slogan (o projeto pagou para uma gráfica fazer a arte para que ela escolhesse) e propostas de divulgação (cartazes, panfletos, anúncios e criação de páginas em redes sociais).

A placa na fachada com o nome do pensionato era pequena (Foto 3), de maneira que se tornava quase imperceptível a visualização pelas pessoas que passavam em frente ao estabelecimento.

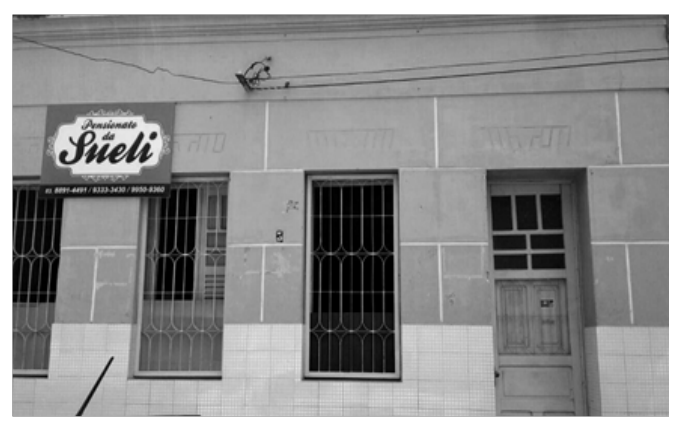

Com a dificuldade de visualização da placa do pensionato, foi sugerida outra logomarca e ampliação da placa, escolhida a critério da proprietária Sueli, para a confecção (Foto 4) cuja descrição é "Pensionato e restaurante da Sueli", tendo como
Foto 2

Oficina de capacitação com Sueli 
slogan: "Sua casa fora de casa".

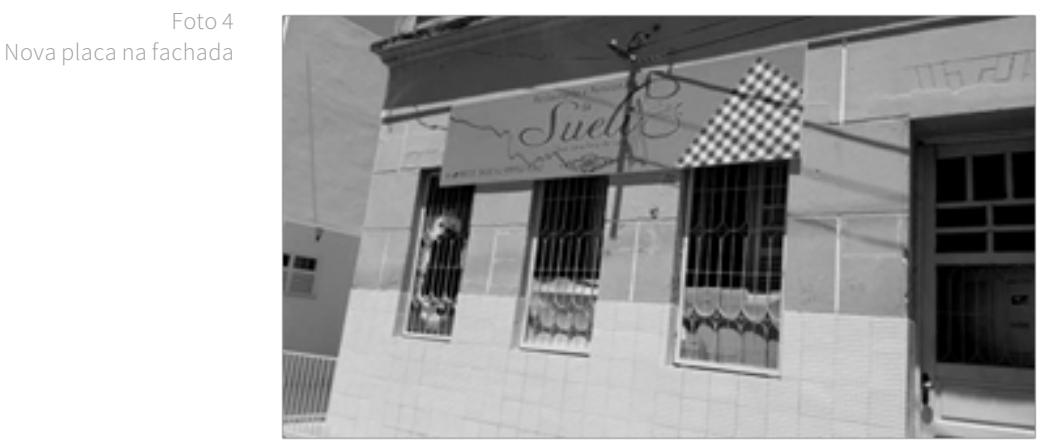

Com as sugestões apresentadas para as demandas e necessidades do pensionato, foi criada uma equipe de alunos que trabalharia aspectos e informações de marketing para o empreendimento, que toda semana auxiliaria a proprietária nas mudanças. Logo, a coordenadora deliberou as novas atividades em grupo, a serem realizadas pelo projeto para continuar a assessoria no empreendimento de dona Sueli, entre as quais foram:

1) Criar uma tabela de preços de todos os produtos e serviços do pensionato e restaurante, colocando a nova logomarca e compartilhar no e-mail do grupo. Posteriormente imprimir e entregar para ela.

2) Criar o cardápio semanal para quentinhas e marmitas, inserindo a nova logomarca e compartilhar no e-mail do grupo. Posteriormente imprimir e entregar para ela.

3) Ministrar a oficina de Planejamento Financeiro na própria pensão. Dar a cartilha para ela.

4) Criação de e-mail e Facebook. Criar e publicar o cardápio com lista de preços e postar fotos das instalações, em grupos de venda e outros.

5) Elaboração de um panfleto (de preferência com 4 por página) e um maior, tipo aviso (folha A4) para distribuição.

6) Acompanhar Sueli na criação do seu livro Caixa e anotações de seus gastos, para ajudar a apurar o custo do seu produto.

Em novembro de 2016, foi realizado o "Pit Stop da Sueli", divulgação do empreendimento Pensionato da Sueli (Foto 5), com panfletagens em pontos estratégicos da cidade de Sousa-PB, com o intuito de captar clientes e gerar receita para o empreendimento.

Seguindo novas orientações, Sueli posteriormente mudou o endereço do estabelecimento para enxugar os custos operacionais, permanecendo, com as atividades de pensionato, restaurante e marmitaria. 


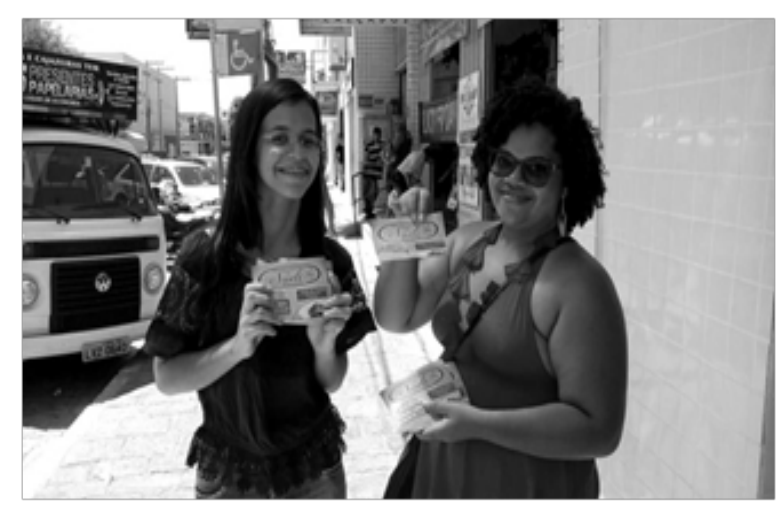

\section{CONCLUSÃO}

O projeto CPMEl, desenvolvido como atividade de extensão universitária, contribuiu significativamente com a prática na formação dos alunos extensionistas, assim como colaborou e proporcionou capacitações e orientações de como gerir o próprio negócio para o mercado, com a qualificação profissional da proprietária da pensão, Dona Sueli.

A atuação do projeto de extensão possibilitou ações de diagnóstico da realidade da Pensão da Sueli, identificando as demandas, necessidades e reais problemas que influenciavam diretamente o desenvolvimento e gestão do empreendimento. A partir da detecção e do diagnóstico dos problemas, como a má gestão financeira, consequência da falta de preparação e qualificação necessária da empreendedora, foi possível atuar efetivamente no aprimoramento do empreendimento por meio de capacitações e cursos de gestão financeira, como também novas ações para divulgação do empreendimento, tornando-o conhecido no mercado, proporcionando a geração de renda e sobrevivência da pensão.

Concluindo, o esforço e desempenho dos envolvidos no projeto já começaram a ser vistos nas primeiras intervenções no Pensionato da Sueli, com a receptividade da empresária em relação à implantação das ideias e abertura às capacitações, além da adoção das sugestões de melhoramento do ambiente interno (layout), externo (placa e fachada), e do novo modelo para controle financeiro e administrativo para a Pensão. Logo, com a implantação e acompanhando inicial das ações foi possível observar um fluxo maior de clientes em busca do empreendimento, mas ainda havendo a necessidade de ajustes no controle financeiro por parte da empresária.

Por fim, entendemos que projetos dessa natureza são importantes para o aprendizado e capacitação dos empreendedores, no intuito de propiciar o desenvolvimento e sobrevivência dos negócios de pequeno porte.

\section{REFERÊNCIAS}

[1] Portal Do Empreendedor-Mei. Microempreendedor Individual - O que é? Disponível em: <http://www. 
REVISTA GUARÁ - Dezembro 2018. ANO VI - NX

Fontes de Financiamento: Conforme Resolução 04/2009, da Câmara Superior de Pesquisa e Extensão da Pró-Reitoria de Pesquisa e Extensão da Universidade Federal de Campina Grande - UFCG, foi disponibilizada uma bolsa para um aluno extensionista no período de oito meses (maio a dezembro de 2016), com parcelas mensais de R\$ 300,00 (trezentos reais). Os demais alunos são extensionistas voluntários.
[2] Luciano, A. Empreendedor: Eu Posso Tornar-me Um? Revista Científica da Faculdade Fleming, Campinas, n. 6 p. 12-16, 2009.

[3] Pereira, E. De Sá. Empreendedorismo e planejamento financeiro na gestão das empresas cadastradas como microempreendedor individual: um estudo de caso no município de Sousa-PB. Monografia de Graduação. UFCG, Sousa, set. 2013.

[4] Lobato, D. M. Administração Estratégica: uma visão orientada para a busca de vantagens competitivas. Rio de Janeiro: Editoração, 2000.

[5] Alday, H. E. C. O Planejamento Estratégico dentro do Conceito de Administração Estratégica. Rev. FAE, Curitiba, V.3, n.2, p. 9-16, maio/ago. 2000.

[6] Lemes Júnior, A. B; Pisa, B. J. Administrando micro e pequenas empresas. Rio de Janeiro: Elsevier, 2010. [7] Forproex - FÓRUM DE PRÓ-REITORES DE EXTENSÃO DAS INSTITUIÇÕES PÚBLICAS DE EDUCAÇÃO SUPERIOR BRASILEIRA. Política Nacional de Extensão Universitária. Gráfica da UFRGS. Porto Alegre, RS, 2012 (Coleção Extensão Universitária; v.7).

[8] Boy, G. A. (1997). The group elicitation method for participatory design and usability testing. Interactions, Vol. 4 (2), p. 27-33. Disponível em: <http://portal.acm.org/citation.cfm?doid=245129.245132>. Acesso em: 12 ago 2016.

\section{Agradecimentos}

Ao setor de transporte da UFCG, na pessoa do Sr. Paulo e todos os motoristas que nos conduziram para as atividades de extensão.

A todos os extensionistas que se empenharam nas ações, e, em especial, a nossa querida empreendedora Sueli Cardoso. Agradecemos a confiança e o empenho para mostrar a realidade de seu empreendimento e compartilhar conhecimento. 